\title{
Clinical characteristics of patients from Quebec, Canada, with Morquio A syndrome: a longitudinal observational study
}

\author{
Lina Moisan ${ }^{1}$, David lannuzzi ${ }^{1}$, Bruno Maranda², Philippe M. Campeau ${ }^{3}$ and John J. Mitchell ${ }^{1,4^{*}}$ (D)
}

\begin{abstract}
Background: Morquio A syndrome is a rare, autosomal recessive, progressively debilitating disorder, with multisystem impairments and high medical burden. Quebec, Canada has a large Morquio A population, which is considered unique due to the presence of founder pathogenic variants. The objectives of this study were to document the genetic and clinical heterogeneity of patients with Morquio A in Quebec, to better characterize the phenotype of those with the French Canadian founder pathogenic variant (NM_000512.5: c.1171A>G, p.Met391Val), and to describe the natural history of the patients treated with elosulfase alfa enzyme replacement therapy. Patients with Morquio A were genotyped for pathogenic variants in the lysosomal enzyme N-acetylgalactosamine-6-sulfatase. Clinical data were retrospectively collected from medical charts of patients and included medical history, height, physical examination, respiratory function tests, electrocardiogram, echocardiogram, endurance in the 6-min walk test (6MWT), and activities of daily living (ADL) as assessed by the Mucopolysaccharidosis Health Assessment Questionnaire (MPS-HAQ). Longitudinal data were collected retrospectively and prospectively for patients treated with elosulfase alfa.
\end{abstract}

Results: A total of 33 patients, aged 5-63 years, were included in the analysis. Patients with the founder pathogenic variant $(n=17)$ generally exhibited a non-classical form of Morquio A. As compared with patients with a non-founder pathogenic variant $(n=16)$, these patients were generally taller, had greater endurance and were better able to perform ADL. However, they still had significant musculoskeletal disease. Most of the 26 patients treated with elosulfase alfa, regardless of pathogenic variant, showed improvements in endurance and ADL. After 5 to 12 months of treatment, the mean improvement from baseline in the 6MWT was $23 \%$ and 10 of 14 patients improved in at least one MPS-HAQ domain. Endurance and ADL generally continued to improve or maintained stable in the long term (up to 7 years). Four out of 19 treated patients with echocardiogram data at follow-up showed progression of cardiac disease.

Conclusions: In Quebec, Canada, Morquio A frequently manifests as a non-classical form of the syndrome due to a founder effect. Patients treated with elosulfase alfa generally show long-term improvement or stability in endurance and function, regardless of pathogenic variant.

Keywords: Canada, Founder effects, Genetic disorders, Mucopolysaccharidosis IVA, Activities of daily living, Walk test

*Correspondence: john.mitchell@muhc.mcgill.ca

${ }^{1}$ Division of Medical Genetics, Montreal Children's Hospital, McGill University Health Centre, Montreal, QC, Canada

Full list of author information is available at the end of the article

\section{Background}

Morquio A syndrome, also called mucopolysaccharidosis IVA (MPS IVA), is an ultra-rare, genetically transmitted lysosomal storage disorder caused by a deficiency of the $N$-acetylgalactosamine-6-sulfatase (GALNS) enzyme $[1,2]$. Deficiency of the GALNS enzyme manifests as a

(c) The Author(s) 2020. This article is licensed under a Creative Commons Attribution 4.0 International License, which permits use, sharing, adaptation, distribution and reproduction in any medium or format, as long as you give appropriate credit to the original author(s) and the source, provide a link to the Creative Commons licence, and indicate if changes were made. The images or other third party material in this article are included in the article's Creative Commons licence, unless indicated otherwise in a credit line to the material. If material is not included in the article's Creative Commons licence and your intended use is not permitted by statutory regulation or exceeds the permitted use, you will need to obtain permission directly from the copyright holder. To view a copy of this licence, visit http://creativeco mmons.org/licenses/by/4.0/. The Creative Commons Public Domain Dedication waiver (http://creativecommons.org/publicdomain/ zero/1.0/) applies to the data made available in this article, unless otherwise stated in a credit line to the data. 
failure to degrade glycosaminoglycans (GAGs), namely keratan sulfate (KS) and chondroitin-6-sulfate (C6S), resulting in excessive accumulation of these GAGs [2] and subsequent activation of secondary pathways of inflammation. The result of the GAG accumulation is a progressively debilitating and potentially life-threatening disorder, with multi-system impairments and a high medical burden [3]. The main organ affected is bone, with accumulation of KS and C6S resulting in impaired development of cartilage and bone and eventual systemic skeletal spondyloepiphyseal dysplasia $[2,4,5]$. The clinical presentation is heterogeneous [6] and typically includes marked skeletal and joint abnormalities, coarsening of facial features, short-trunk dwarfism with short neck, restrictive and obstructive lung disease, impaired cardiac function, hearing and vision loss, abdominal manifestations (hepatomegaly, hernias), waddling gait leading to increased fall risk, and dental abnormalities $[4,5,7]$. Classical forms of Morquio A syndrome are also associated with fatigue, sleep apnea, shortness of breath, tracheal obstruction, and recurrent upper respiratory tract infections [5]. Over time, the progressive loss of functional capacity and endurance leads to reduced quality of life [3]. Many individuals become wheelchair-dependent and require multiple surgeries $[3,6]$. Morquio A patients typically have a shortened life expectancy, with the main cause of death being respiratory failure $[6,8]$.

Available prevalence data for Morquio A syndrome are derived from epidemiologic studies conducted in individual countries. The birth prevalence ranges from 1 per 71,000 in the United Arab Emirates to 1 in 500,000 in Japan, with most countries having $<0.5$ cases per 100,000 live births [9]. Morquio A appears to be more prevalent than in most countries in Quebec, Canada, although precise numbers are not available. In 1973, a survey of the main hospitals in Quebec conducted by Gadbois et al. identified 48 patients with the disease distributed within 27 families [10]. The high prevalence of Morquio A in Quebec is explained by the fact that French Canadians represent a unique population with a higher rate of some recessive genetic diseases that reflects the presence of founder pathogenic variants [11].

Treatment of Morquio A syndrome has traditionally been supportive in nature, with the goals of managing symptoms with physical therapy and surgery [7]. Enzyme replacement therapy with elosulfase alfa $\left(\right.$ VIMIZIM $^{\circledR}$, BioMarin Pharmaceutical Inc, CA, USA) was approved by the US Food and Drug Administration in February 2014, by the European Medicines Agency in April 2014, and by Health Canada in September 2014 [12]. Approvals were based on the findings of a 24-week, placebocontrolled, Phase 3 trial that randomized 176 patients [13]. Once-weekly intravenous infusions of elosulfase alfa
( $2 \mathrm{mg} / \mathrm{kg}$ ) significantly improved endurance based on the 6-min walk test (6MWT), and the most common adverse events were infusion-related reactions and hypersensitivity [13]. These improvements were sustained over 120 weeks among patients participating in an extension study of the trial [14]. Another long-term study showed no trends towards decreasing endurance and maintained tolerability and safety over 5 years in 17 patients, many of whom elected to be treated with home infusions [15].

Canadian patients with Morquio A syndrome face substantial barriers to accessing elosulfase alfa treatment because of the absence of an orphan drug plan in Canada and marked differences in approval processes across provinces [16]. Given the cost of orphan medications and possible pharmacogenetic effects in the Quebec population, data supporting clinical efficacy are critical. This report documents the genetic and clinical heterogeneity of Morquio A syndrome in a series of patients from Quebec, and describes longitudinal data from those treated with elosulfase alfa.

\section{Methods \\ Study design and objectives}

This was a longitudinal observational study of patients with Morquio A syndrome in Quebec, Canada. All patients with a confirmed Morquio A diagnosis who provided consent to participate in the study are included.

The main objectives of the study were to document the genetic and clinical heterogeneity of the Morquio A patient population in Quebec in general, to characterize the phenotype of patients with the French Canadian founder pathogenic variant (NM_000512.5: c.1171A >G, p.Met391Val), and to describe the disease course of those treated with elosulfase alfa.

The study protocol was approved by the institutional review board at McGill University. All patients (or their guardians) provided written informed consent before study entry. The study was conducted in accordance with the Declaration of Helsinki and International Conference of Harmonization Good Clinical Practice guidelines [17].

\section{Genetic testing}

All patients were genotyped for pathogenic variants in GALNS. Patients were stratified by the presence or absence of the French Canadian founder pathogenic variant c.1171A $>$ G, p.Met391Val. Patients with at least one copy of this pathogenic variant were included in the founder pathogenic variant group, regardless of the presence of other pathogenic variants (because of suggestions that, in compound heterozygotes, the phenotype of the allele with residual activity will be displayed [18]). 


\section{Data collection}

Clinical data were retrospectively collected from November 2009 to December 2014 and prospectively from January 2015 to May 2019 via chart review of medical records. Clinical data were collected approximately every 6 months or at every clinic visit [7]. Clinical assessments for which data are presented include medical history, height (z-score was calculated [19]), physical examination, respiratory function tests (forced expiratory volume in $1 \mathrm{~s}\left[\mathrm{FEV}_{1}\right]$ and forced vital capacity [FVC]), electrocardiogram, echocardiogram, endurance, and activities of daily living (ADL). Endurance was assessed by the 6MWT [7]. ADL were assessed by the MPS Health Assessment Questionnaire (MPS-HAQ; originally developed for patients with MPS I [13]). The MPS-HAQ assesses self-care (eating/drinking, dressing, bathing, grooming, tooth brushing, and toileting), mobility (dexterity, mobility, walking, stair climbing, and gross motor skills), and caregiver-assistance required (Care Services) [20]. Total self-care and mobility domain scores range from 0 (not difficult at all) to 10 (extremely difficult) and 11 (unable to do). The total Care Services domain score ranges from 13 (independent) to 52 (complete assistance required) [20]. Decreasing scores imply improvements.

For some of the patients, some data could retrospectively be collected from the MOR-001 natural history study (NCT00787995; [1, 21]), the Phase 3 MOR-004 and MOR-005 studies (NCT01275066 and NCT01415427; [13, 14]), and the Phase 2 MOR-008 study (NCT01609062; [22]), and were included in this study.

\section{Statistical analysis}

Descriptive statistics were used to summarize data. Baseline data are presented for all patients. For patients initiating elosulfase alfa therapy, data at baseline and at last follow-up are presented. Baseline was defined as the closest measurement prior to, or on the day of, first treatment for patients treated with elosulfase alfa, and as the first measurement recorded for the other patients. For baseline measurements and change from baseline, the founder pathogenic variant group was compared with the non-founder pathogenic variant group by an unpaired $t$ test of unequal variance $(P<0.05$ was considered significant). Missing data was not included in the analysis.

\section{Results}

\section{Demographic and baseline clinical characteristics}

We evaluated 33 patients with Morquio A syndrome from Quebec who provided consent to participate in the study (Table 1$)$. There were more males $(58 \%)$ than females (42\%) in the overall population. Mean age was 25.9 years (range: 5-63 years; median: 21 years), and the mean height of adults $(\mathrm{n}=23)$ was $1.23 \mathrm{~m}$. As determined based on height data, compared with Morquio A-specific growth charts [23], phenotype was determined as classical in 12 patients, non-classical in 16 patients, and intermediate in five patients (Table 1). Four patients previously participated in the MOR-001 natural history study (patients $2,19,26$, and 27), four in the MOR-004 and MOR-005 studies (patients 3, 7, 25, and 29 ), and three in the MOR-008 study (patients 26, 27, and 34 ). Twenty six patients had received treatment with elosulfase alfa. In these patients, elosulfase alfa was administered according to labeling as $2 \mathrm{mg} / \mathrm{kg}$ intravenously once every week.

Ejection fraction was available for 15 patients, and was within normal limits (55-70\%) in these patients. Lung function data were available for 20 patients; $\mathrm{FEV}_{1} / \mathrm{FVC}$ ratio was within the normal range $(>70 \%)$ in most of these patients (Table 2). It should be noted that for many patients, it was difficult to interpret $\mathrm{FEV}_{1}$ and $\mathrm{FVC}$ data as \% predicted cannot be calculated for individuals with short stature for whom norms are not available. Eleven out of 26 patients with available echocardiogram data had evidence of cardiac abnormalities. These included ten patients with valve disease and one patient with ascending aorta dilatation that worsened over time (see footnote Table 2 for details). These abnormalities were of clinical significance in six patients (patients 2, 8, 11, 19, 25, and 31 ). Two patients (11 and 12), both with a non-founder pathogenic variant and significant respiratory involvement died during the study due to cardiac arrest. These patients were siblings and died 1 year apart. They both had classical disease and significant respiratory involvement. Patient 11 had a previous cardiac arrest, and death occurred during activity, likely due to arrhythmia. Patient 12 died in same manner. The exact cause of death could not be determined, as there was no autopsy. Four patients (see footnote Table 2 for details) had difficulty sustaining respiratory efforts and pulmonary function could not be measured.

Genetic data were available for all patients; 17 patients expressed at least one copy of the French Canadian founder pathogenic variant (c.1171A>G, p.Met391Val), five of which were homozygotes, and 16 patients had only non-founder pathogenic variants (Table 1).

\section{Disease traits related to founder pathogenic variant}

Patients with the founder pathogenic variant tended to exhibit a non-classical form of Morquio A syndrome, while most patients without the founder pathogenic variant had a classical phenotype (Tables 1, 2 and 3, Fig. 1). Although most patients, regardless of pathogenic variant, were substantially shorter than normalized World Health Organization values, patients with the founder 
Table 1 Baseline characteristics of individual patients with Morquio A syndrome

\begin{tabular}{|c|c|c|c|c|c|c|c|c|}
\hline ID & \multicolumn{2}{|c|}{ GALNS pathogenic variants } & \multirow[t]{2}{*}{ Sex } & \multirow[t]{2}{*}{ Age (years) } & \multirow[t]{2}{*}{ Height z-score ${ }^{b}$} & \multirow[t]{2}{*}{$\begin{array}{l}\text { Adult height } \\
(\mathrm{m})^{\mathrm{a}}\end{array}$} & \multirow[t]{2}{*}{$\begin{array}{l}\text { Elosulfase alfa } \\
\text { treatment }\end{array}$} & \multirow[t]{2}{*}{ Phenotype $^{c}$} \\
\hline Foun & pathogenic varia & group & & & & & & \\
\hline 1 & $1171 A>G$ & $121 \mathrm{~A}>\mathrm{T}$ & M & 43 & -4.1 & 1.47 & No & NC \\
\hline 3 & $1171 A>G$ & $901 \mathrm{G}>\mathrm{T}$ & $\mathrm{F}$ & 23 & -5.8 & 1.23 & Yes & NC \\
\hline 7 & $1171 \mathrm{~A}>\mathrm{G}$ & $1171 \mathrm{~A}>\mathrm{G}$ & $\mathrm{F}$ & 25 & -4.8 & 1.25 & Yes & NC \\
\hline 17 & $1171 A>G$ & 405_422+1del & $\mathrm{F}$ & 60 & -6.8 & 1.19 & No & NC \\
\hline 18 & $1171 A>G$ & 841_867_del & $\mathrm{F}$ & 36 & -4.3 & 1.36 & Yes & NC \\
\hline 20 & $1171 \mathrm{~A}>\mathrm{G}$ & $1171 \mathrm{~A}>\mathrm{G}$ & $\mathrm{F}$ & 14 & -2.5 & - & Yes & NC \\
\hline 21 & $1171 A>G$ & 405_422+1del & $\mathrm{F}$ & 58 & -6.5 & 1.25 & Yes & NC \\
\hline 22 & $1171 A>G$ & $121 \mathrm{~A}>\mathrm{T}$ & M & 7 & -7.8 & - & Yes & I \\
\hline 24 & $1171 A>G$ & $121 \mathrm{~A}>\mathrm{T}$ & M & 45 & -6.1 & 1.32 & Yes & I \\
\hline 26 & $1171 A>G$ & 1354T>A & M & 21 & -1.6 & 1.67 & Yes & NC \\
\hline 27 & $1171 A>G$ & $1354 \mathrm{~T}>\mathrm{A}$ & $\mathrm{F}$ & 17 & -1.6 & - & Yes & NC \\
\hline 29 & $1171 A>G$ & 404_422del19 & $\mathrm{F}$ & 17 & -5.4 & - & Yes & NC \\
\hline 30 & $1171 A>G$ & $1157 \mathrm{G}>\mathrm{A}$ & M & 36 & -6.1 & 1.32 & Yes & I \\
\hline 31 & $1171 \mathrm{~A}>\mathrm{G}$ & $1171 A>G$ & M & 40 & -4.9 & 1.39 & Yes & NC \\
\hline 32 & $1171 A>G$ & $121 \mathrm{~A}>\mathrm{T}$ & $\mathrm{F}$ & 40 & -5.5 & 1.27 & No & NC \\
\hline 33 & $1171 \mathrm{~A}>\mathrm{G}$ & $1171 \mathrm{~A}>\mathrm{G}$ & M & 23 & -3.1 & 1.41 & No & NC \\
\hline 34 & $1171 A>G$ & $1171 A>G$ & $\mathrm{~F}$ & 16 & -1.4 & - & Yes & NC \\
\hline \multicolumn{9}{|c|}{ Non-founder pathogenic variant group } \\
\hline 2 & $244+1 G>T$ & $901 \mathrm{G}>\mathrm{T}$ & M & 27 & -7.5 & 1.21 & Yes & C \\
\hline 4 & $901 \mathrm{G}>\mathrm{T}$ & $121 \mathrm{~A}>\mathrm{T}$ & M & 12 & -7.6 & - & Yes & C \\
\hline 5 & $901 \mathrm{G}>\mathrm{T}$ & $121 \mathrm{~A}>\mathrm{T}$ & M & 10 & -4.6 & - & Yes & 1 \\
\hline 6 & $901 \mathrm{G}>\mathrm{T}$ & $704 C>A$ & $\mathrm{~F}$ & 9 & -7.1 & - & Yes & C \\
\hline 8 & $901 \mathrm{G}>\mathrm{T}$ & $319 G>A$ & M & 16 & -6.7 & - & Yes & C \\
\hline 9 & $121 \mathrm{~A}>\mathrm{T}$ & 841_867_del & $\mathrm{F}$ & 63 & -6.9 & 1.05 & Yes & 1 \\
\hline 11 & $901 \mathrm{G}>\mathrm{T}$ & 405_422+1_del & M & 27 & -11.1 & 0.92 & Yes & C \\
\hline 12 & $901 \mathrm{G}>\mathrm{T}$ & 405_422+1_del & M & 25 & -10.4 & 0.98 & Yes & C \\
\hline 13 & $901 \mathrm{G}>\mathrm{T}$ & $121 \mathrm{~A}>\mathrm{T}$ & $\mathrm{F}$ & 35 & -8.0 & 1.15 & Yes & NC \\
\hline 14 & $1157 G>A$ & $1157 G>A$ & M & 15 & -5.6 & - & No & $C$ \\
\hline 15 & $1157 G>A$ & $1157 G>A$ & M & 21 & -11.0 & 0.92 & No & $C$ \\
\hline 16 & $1157 G>A$ & $1157 \mathrm{G}>\mathrm{A}$ & M & 19 & -11.5 & - & No & $C$ \\
\hline 19 & $244 T>C$ & $244 \mathrm{~T}>\mathrm{C}$ & $\mathrm{F}$ & 20 & -1.9 & 1.36 & Yes & $\mathrm{NC}$ \\
\hline 23 & $901 \mathrm{G}>\mathrm{T}$ & $901 \mathrm{G}>\mathrm{T}$ & M & 5 & -5.2 & - & Yes & $C$ \\
\hline 25 & 406_424del19 & $1480 A>G$ & M & 15 & -7.2 & - & Yes & C \\
\hline 28 & $938 \mathrm{C}>\mathrm{T}$ & $938 \mathrm{TC}>\mathrm{T}$ & M & 16 & -7.8 & - & Yes & C \\
\hline
\end{tabular}

Bold indicates a homozygote founder pathogenic variant

Patient 10 withdrew consent and is therefore not included in the analysis

$1171 \mathrm{~A}>\mathrm{G}$ : founder pathogenic variant; F: female; GALNS: N-acetylgalactosamine-6-sulfatase gene; ID: patient identification number; M: male; NA: not available

a Adult height is only presented for patients $\geq 18$ years of age

b Z-score was calculated at https://apps.cpeg-gcep.net/quickZ_WHO

c Phenotypes were determined based on Morquio A-specific growth charts [23]: patients were classified as classical (C) when height was $\leq 50$ th $\%$ ile, as intermediate (I) when height was $>50$ th and $<75$ th $\%$ ile, and as non-classical (NC) when height was $\geq 75$ th \%ile

pathogenic variant were significantly $(P=0.001)$ taller by $\mathrm{z}$-score than most patients in the non-founder group (Fig. 1a). Nevertheless, many of the founder patients still had significant musculoskeletal disease. Patients with the founder pathogenic variant could also walk slightly farther during the $6 \mathrm{MWT}$ than non-founder patients, though the difference was not statistically significant $(P=0.281)$ (Fig. 1b). In addition, patients with the founder pathogenic variant had better ability to perform ADL, as measured with the MPS-HAQ, compared with patients with a non-founder pathogenic variant; the domains of self-care, mobility, and care services 
Table 2 Cardiac and lung function of individual patients at baseline and after elosulfase alfa treatment

\begin{tabular}{|c|c|c|c|c|c|c|c|}
\hline \multirow[t]{3}{*}{ ID } & \multirow[t]{3}{*}{$\begin{array}{l}\text { Cardiac abnormalities } \\
\text { at baseline }\end{array}$} & \multicolumn{3}{|c|}{ Ejection fraction $(\%)^{a}$} & \multicolumn{3}{|c|}{$\begin{array}{l}\text { Lung function } \\
\text { FEV }_{1} / \text { FVC }(\%)^{c}\end{array}$} \\
\hline & & \multirow[t]{2}{*}{ Baseline } & \multicolumn{2}{|c|}{ Elosulfase alfa treatment } & \multirow[t]{2}{*}{ Baseline } & \multicolumn{2}{|c|}{ Elosulfase alfa treatment } \\
\hline & & & Follow-up & Duration & & Follow-up & Duration \\
\hline \multicolumn{8}{|c|}{ Founder pathogenic variant group } \\
\hline 1 & No & 70 & NT & & 73 & NT & \\
\hline 3 & No & NA & 65 & 6.5 years & 91 & 91 & 2 years \\
\hline 7 & No & NA & 65 & 4.5 years & 85 & 85 & 6 years \\
\hline 17 & NA & NA & NT & & NA & NT & \\
\hline 18 & No & $>50$ & 60 & 3 years & 88 & 86 & 3 years \\
\hline 20 & Yes & NA & 67 & 4 years & 81 & 88 & 7 years \\
\hline 21 & Yes & 75 & NA & & 84 & NA & \\
\hline 22 & NA & NA & NA & & 87 & 92 & 2.5 years \\
\hline 24 & No & NA & 70 & 6 months & NA & 80 & 2 years \\
\hline 26 & No & NA & 61 & 2 years & 86 & 82 & 6 years \\
\hline 27 & No & NA & 65 & 5 years & 83 & 83 & 5 years \\
\hline 29 & No & 59 & 49 & 5 years & 91 & 91 & 6.5 years \\
\hline 30 & No & 60 & NA & & NA & & \\
\hline 31 & Yes $^{d}$ & NA & 70 & 6 months & NA & 86 & 2 years \\
\hline 32 & No & 74 & NT & & NA & NT & \\
\hline 33 & No & NA & NT & & 86 & NT & \\
\hline 34 & NA & NA & 60 & 1 year & 89 & 89 & 6 years \\
\hline \multicolumn{8}{|c|}{ Non-founder pathogenic variant group } \\
\hline 2 & Yes & NA & NA & & 91 & 90 & 1.5 years \\
\hline 4 & NA & NA & NA & & NA & NA & \\
\hline 5 & No & NA & 59 & 1 year & NA & NA & \\
\hline 6 & Yes & 67 & NA & & NA & NA & \\
\hline 8 & Yes & 78 & 82 & 3 years & 84 & 100 & 3 years \\
\hline 9 & Yes & 70 & 65 & 3 years & 79 & 77 & 3 years \\
\hline 11 & Yes & 70 & 65 & 1 year & NA & NA & \\
\hline 12 & No & 55 & 55 & 3 years & NA & 68 & 3 years \\
\hline 13 & No & NA & NA & & NA & NA & \\
\hline 14 & NA & 60 & NT & & 71 & NT & \\
\hline 15 & NA & 78 & NT & & 101 & NT & \\
\hline 16 & NA & 69 & NT & & 71 & NT & \\
\hline 19 & Yes & NA & NA & & 85 & 86 & 4 years \\
\hline 23 & No & NA & NA & & NA & NA & \\
\hline 25 & Yes & 62 & NA & & 98 & NA & \\
\hline 28 & Yes & NA & 79 & 1 year & NA & 92 & 1 year \\
\hline
\end{tabular}

For patients who received elosulfase alfa, the baseline measurement (closest measurement prior to, or on the day of, first treatment) was included. For other patients, the first measurement recorded is included in the table

FEV 1 forced expiratory volume in $1 \mathrm{~s}, F V C$ forced vital capacity, ID patient identification number, NA not available, NT no elosulfase alfa treatment

a Normal range $55-70 \%$

b Pulmonary abnormalities included the following: Patients 8, 9, 25, and 29 had difficulty sustaining respiratory efforts

c Normal range $\geq 70 \%$

d Baseline echographic examination of subject 31 was performed 4 months after initiating elosulfase alfa

e Cardiac abnormalities included the following: Patient 2 had a mitral valve insufficiency and aortic valve stenosis; Patient 6 had a thickened aortic valve and mitral valve with trivial mitral regurgitation; Patient 8 had ascending aorta dilatation that worsened overtime; Patient 9 had atrioventricular valve sclerosis; Patient 11 had mitral valve thickening and aortic valve replacement; Patient 19 had pulmonary valve stenosis and pulmonary artery dilation; Patient 20 had mild pulmonary and tricuspid regurgitation; Patient 21 had atrioventricular valve sclerosis; Patient 25 had moderate mitral valve regurgitation and left ventricular outflow obstruction; Patient 28 had a slight reformation of the mitral valve; and Patient 31 had a bicuspid aortic valve and aortic root dilation 
Table 3 Baseline 6MWT and MPS-HAQ results of individual patients

\begin{tabular}{lllll}
\hline ID & Endurance & & MPS-HAQ & \\
\cline { 3 - 5 } & 6MWT $(\mathrm{m})$ & $\mathrm{SC}$ & MOB & $\mathrm{CS}$
\end{tabular}

\begin{tabular}{lllll}
\hline Founder pathogenic variant group & & & \\
1 & 27 & 3.1 & 6.6 & 22 \\
3 & 321 & 0.2 & 4.7 & 23 \\
7 & 138 & 0.7 & 6.3 & 26 \\
17 & $\mathrm{NM}$ & 2.4 & 5.7 & 14 \\
18 & 371 & $\mathrm{NA}$ & $\mathrm{NA}$ & $\mathrm{NA}$ \\
20 & 246 & 1.9 & 3.3 & 23 \\
21 & 330 & 1.2 & 2.2 & 23 \\
22 & $\mathrm{NA}$ & $\mathrm{NA}$ & $\mathrm{NA}$ & $\mathrm{NA}$ \\
24 & 230 & 1.2 & 5.7 & 13 \\
26 & 423 & 0.4 & 2.1 & 15 \\
27 & 338 & 0.04 & 1.6 & 14 \\
29 & 123 & 2.1 & 4.5 & 21 \\
30 & $\mathrm{NM}$ & 5.2 & 8.6 & 20 \\
31 & 535 & 1.5 & 2.5 & 13 \\
32 & $\mathrm{NA}$ & 0.8 & 2.7 & 13 \\
33 & $\mathrm{NM}$ & 0.3 & 5.6 & 33 \\
34 & 347 & $\mathrm{NA}$ & $\mathrm{NA}$ & NA
\end{tabular}

Non-founder pathogenic variant group

$\begin{array}{lllll}2 & \text { NM } & 8.8 & 9.8 & 47 \\ 4 & 289 & 2.7 & 1.2 & 17 \\ 5 & 458 & 1.5 & 0.9 & 19 \\ 6 & 261 & \text { NA } & \text { NA } & \text { NA } \\ 8 & 225 & \text { NA } & \text { NA } & \text { NA } \\ 9 & \text { NM } & 9.5 & 10.0 & 51 \\ 11 & \text { NM } & 9.2 & 10.0 & 52 \\ 12 & \text { NM } & 2.9 & 8.3 & 42 \\ 13 & 439 & 0.4 & 3.1 & 13 \\ 14 & 141 & 4.4 & 8.0 & 37 \\ 15 & \text { NM } & 7.6 & 10.0 & 48 \\ 16 & 25 & 5.2 & 9.0 & 37 \\ 19 & 171 & 3.2 & 5.6 & 36 \\ 23 & \text { NA } & 4.1 & 1.5 & 30 \\ 25 & 120 & 5.1 & 8.7 & 28 \\ 28 & 36 & \text { NA } & \text { NA } & \text { NA }\end{array}$

For patients who received elosulfase alfa, the baseline measurement (closest measurement prior to, or on the day of, first treatment) was included. For other patients, the first measurement recorded is included in the table

6MWT 6-min walk test, CS care services, ID patient identification number, $M O B$ mobility, MPS-HAQ Mucopolysaccharidosis Health Assessment Questionnaire, $N A$ not available, $N M$ not mobile, $S C$ self-care

were all better (lower scores) for those with the founder pathogenic variant $(P=0.001, P=0.075$, and $P=0.001$, respectively) (Fig. 1c). Finally, patients with the founder pathogenic variant showed less cardiac abnormalities and impairments in respiratory function than those with non-founder pathogenic variants.
Longitudinal data of patients treated with elosulfase alfa Of the 26 patients who had received treatment with elosulfase alfa; 13 had a founder pathogenic variant and 13 had a non-founder pathogenic variant. The duration of treatment varied from 6 months to 7 years.

For patients treated with elosulfase alfa and assessed between 5 and 12 months after the start of treatment, changes from baseline in 6MWT and MPSHAQ results were variable (Fig. 2). However, there was no significant difference between patients with the founder or non-founder pathogenic variant at 5 to 12 months for either $6 \mathrm{MWT}(P=0.896)$ or MPS-HAQ (self-care $P=0.1134$; mobility $P=0.3423$; care services $P=0.806$ ). Importantly, many patients from both groups showed improvements in the 6MWT within this timeframe (Fig. 2). The mean improvement in the $6 \mathrm{MWT}$ for all patients, regardless of pathogenic variant, was $23 \%$. For the MPS-HAQ, we observed $\geq 10 \%$ improvement (decrease in score) in at least one domain in 10 of 14 patients with available data, regardless of pathogenic variant; seven patients improved in at least two domains, and three patients improved in all three domains. Some patients had low baseline scores with little room for improvement. In general, patients showing initial improvements were able to sustain these over long-term treatment (Fig. 2).

Patients treated with elosulfase alfa for a longer time showed improvements in the 6MWT regardless of pathogenic variant (Fig. 3a, b). In both groups, improvements in endurance were generally maintained, or continued to improve, over many years of treatment. MPS-HAQ results in the long term were more variable, but several patients showed long-term improvements, regardless of pathogenic variant (Fig. 4). Overall, the spread of MPS-HAQ scores for patients with non-founder pathogenic variants was greater than for those with the founder pathogenic variant (Fig. 4), perhaps because phenotypes within the founder group were more uniform than within the non-founder group, which showed a wider variation of phenotypes.

Overall, ejection fraction and $\mathrm{FEV}_{1} / \mathrm{FVC}$ ratio of patients treated with elosulfase alfa remained stable over time (for up to 7 years), regardless of pathogenic variant (Table 2). Four out of 19 treated patients with echocardiogram data at follow-up showed progression of cardiac disease (patients 2, 11, 19, and 25, all from the non-founder pathogenic variant group).

Longitudinal data of untreated patients are not presented as data for these patients were too limited to make any meaningful comparison with treated patients. 
a Height Z-score

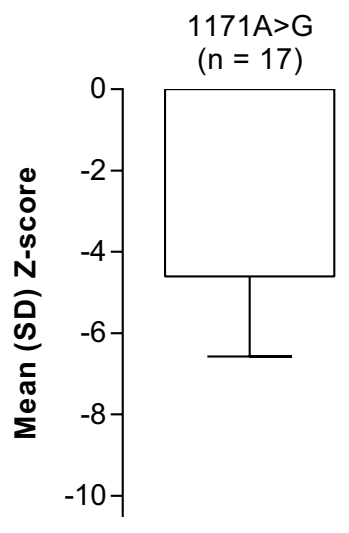

Non-1171A>G $(n=16)$

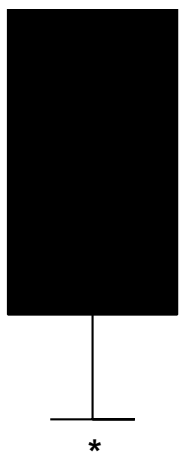

C MPS-HAQ

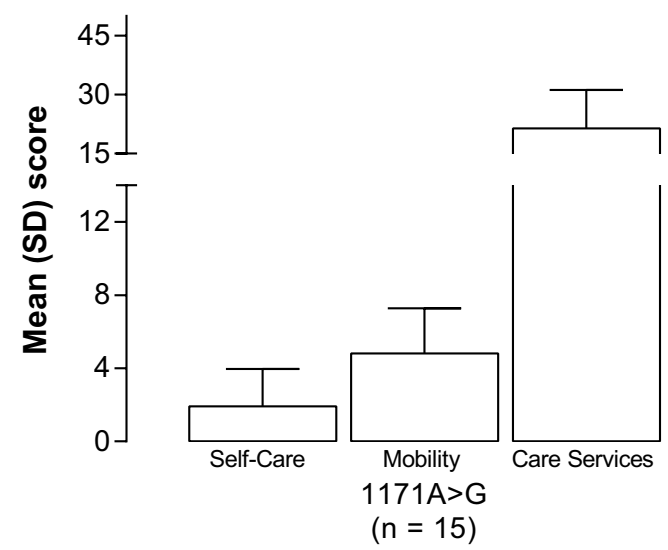

b 6-minute walk test
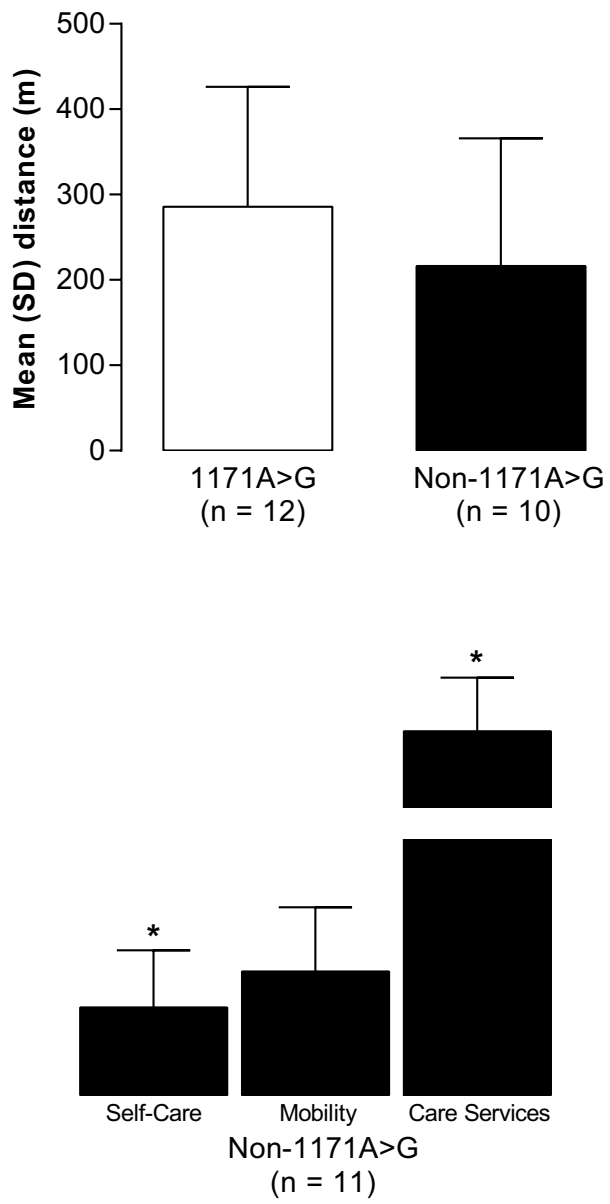

Fig. 1 Baseline measures. a Mean $\pm S D$ height z-score (for children) or SD from the average of people of the same age and sex (for adults), $\mathbf{b}$ Mean \pm SD distance in the 6 -min walk test, and $\mathbf{c}$ mean \pm SD score for the self-care, mobility, and care services domains of the MPS-HAQ. $1171 \mathrm{~A}>\mathrm{G}$ : founder pathogenic variant; MPS-HAQ: Mucopolysaccharidosis Health Assessment Questionnaire; SD: standard deviation. ${ }^{*} P=0.001$

\section{Discussion}

This is the first report of Morquio A syndrome in French Canadians from Quebec in over 45 years. In 1973, Gadbois and colleagues described the physical appearance and biochemical characteristics of 48 Quebecois with the disease [10]. Our observations expand on these data and highlight the phenotypic variability in this unique population. Over half of our patient sample expressed the French Canadian founder pathogenic variant in GALNS (i.e., c.1171A $>$ G, p.Met391Val). This pathogenic variant appears to be associated with a more non-classical form of Morquio A syndrome than most non-founder pathogenic variants, as shown by a greater mean adult height, a better endurance and ability to perform ADL, and less cardiac abnormalities and impairments in lung function. The majority of patients received treatment with elosulfase alfa. These patients generally showed improvements over time in 6MWT and MPS-HAQ outcomes, regardless of whether or not they had the French Canadian founder pathogenic variant.

The improvements in the 6MWT and MPS-HAQ observed in the patients receiving elosulfase alfa were similar to those observed in international clinical trials. In the Phase 3 trial, patients randomized to elosulfase alfa $2 \mathrm{mg} / \mathrm{kg}$ for 24 weeks $(\mathrm{n}=58)$ showed a mean improvement in 6MWT distance of $17.9 \%$ over baseline (versus 6.4\% for placebo; $\mathrm{n}=59$ ) [13]. This is similar to the findings in our study (23\% improvement over baseline after 5-12 months, regardless of pathogenic variant), and above the mean minimal clinically important difference in the 6MWT estimated for respiratory, cardiovascular, and muscular diseases (7-9\%) [4]. In the Phase 3 extension trial, 6MWT remained stable with elosulfase alfa treatment over 120 weeks [14], while two sequential open-label studies in 17 patients showed sustained improvements over up to 5 years of treatment [15]. These 


$$
\begin{aligned}
& \text { - No change } \\
& \geq 10 \% \text { improvement } \\
& \geq 10 \% \text { worsening } \\
& \text { No measure available }
\end{aligned}
$$

\begin{tabular}{|c|c|c|}
\hline 3 & 0 & 0 \\
\hline 7 & 0 & 0 \\
\hline 18 & 0 & 0 \\
\hline 20 & 0 & 0 \\
\hline 21 & 0 & 0 \\
\hline 24 & 0 & 0 \\
\hline 26 & 0 & 0 \\
\hline 27 & 0 & 0 \\
\hline 29 & 0 & 0 \\
\hline 30 & 0 & 0 \\
\hline 31 & 0 & 0 \\
\hline 34 & 0 & 0 \\
\hline
\end{tabular}
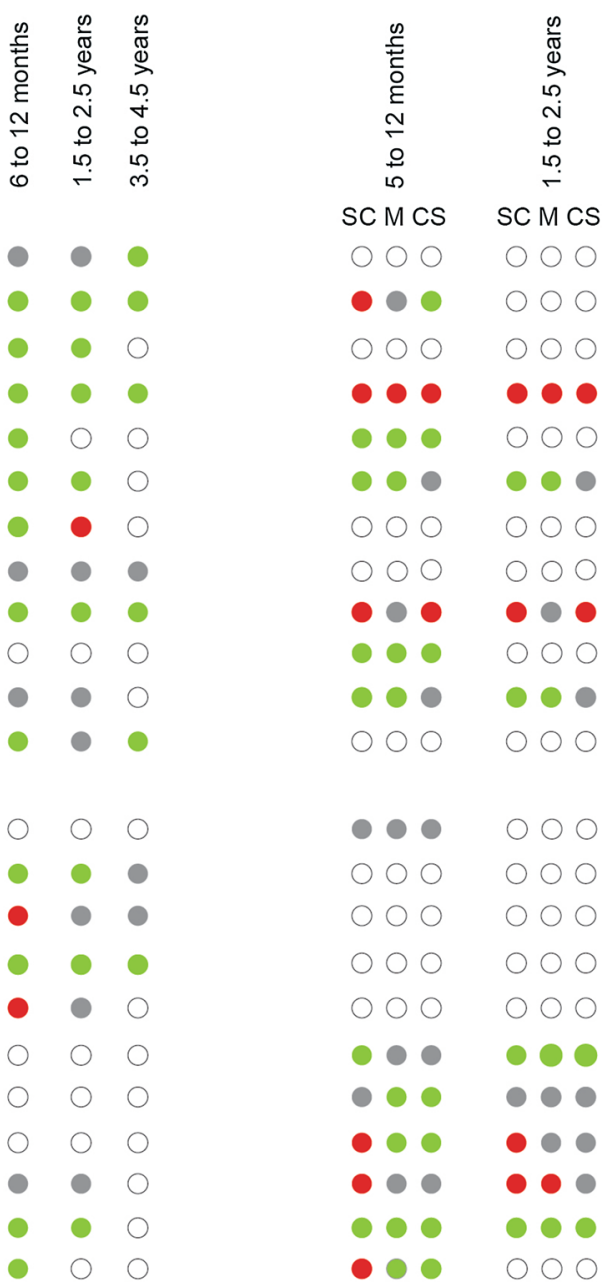

Fig. 2. $6 M W T$ and MPS-HAQ results in patients treated with elosulfase alfa after 5 or 6 to 12 months, 1.5 to 2.5 years, and (for 6MWT) 3.5 to 4.5 years. Individual patient responses in 6MWT and MPS-HAQ were classified as no change from baseline, $\geq 10 \%$ improvement (longer distance on the 6MWT or lower score on the MPS-HAQ) from baseline, $\geq 10 \%$ worsening (shorter distance on the 6MWT or higher score on the HAQ) from baseline, or no measure available. Note that the closest measurement to, but not exceeding, the largest time of treatment was included. For 6MWT, some patients $(5,13$, and 31) had normal 6MWT for height [29], and patient 26 had a decrease in 6MWT at 1.5 to 2.5 years because of back surgery (but returned to normal 6MWT for height in later years). 1171 A>G: founder pathogenic variant; 6MWT: 6-min walk test; CS: care services; MPS-HAQ: Mucopolysaccharidosis Health Assessment Questionnaire; M: mobility; SC: self-care clinical trial results are also similar to our findings of $6 \mathrm{MWT}$ improvements or maintenance over a period of up to 7 years. In addition, we observed improvements in MPS-HAQ outcomes, similar to those seen in the Phase 3 clinical trial $[20,24]$. It should be kept in mind that $6 \mathrm{MWT}$ distance increases with age and height in children, which may partly explain long-term increases in the test in younger patients [25, 26]. Nevertheless, longterm increases or stability in the 6MWT were also seen in most adult patients. These long-term results should be interpreted in light of the progressive nature of Morquio A. Published natural history data have shown a gradual decline in 6MWT and MPS-HAQ results over time in the absence of treatment $[1,14,20]$. The finding that most patients in our study showed stable or improved endurance and/or MPS-HAQ scores over time indicates that elosulfase alfa can slow down the gradual regression in these measures.

The findings of our study contribute to a better understanding of the clinical characteristics and genetic underpinnings in Quebecois, as well as the natural history of the disease in those receiving elosulfase alfa. Although elosulfase alfa, the first and only medical therapy available to modify the disease at a cellular level, has been approved in Canada for patients with Morquio A syndrome, treatment poses a sizeable economic burden to patients. There are currently no conditions for coverage by the Quebec Public Prescription Drug Insurance Plan (elosulfase alfa can only be prescribed through exceptional patient status) and no formal guidelines that provide criteria for its use. Instead, there is considerable debate and policy discussion, particularly with regard to cost and which patients are most likely to benefit. Our data support the international and Canadian management guidelines for Morquio A, which recommend initiation of treatment as early as possible in light of the progressive nature of the disease [27, 28]. Given the clinical heterogeneity, individual treatment goals should be established by a multidisciplinary team taking into account the disease burden at the time of treatment initiation and the anticipated measurable benefits over time.

Several limitations of our study should be acknowledged. Though observational studies are useful in identifying relationships between characteristics, such as associations between genetic pathogenic variants and phenotype, causality cannot be established in the absence of a more stringent methodology involving required clinic visits and formal statistical analyses of variance with a complete data set. In addition, this study had no restrictions on surgery, other treatments, or activities before a clinic visit, and all could have influenced the assessments at that visit. 6MWT, respiratory function tests and echocardiograms were often performed locally, 

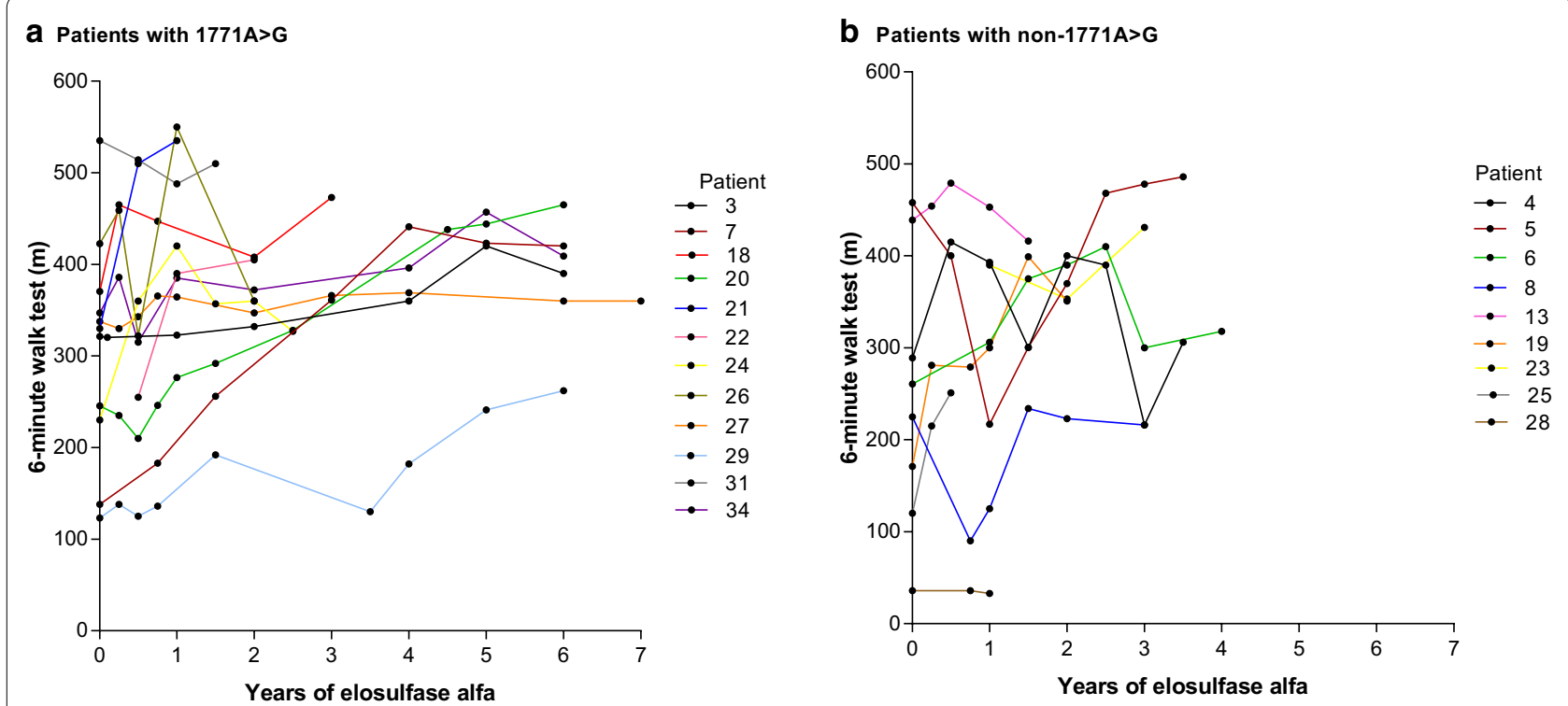

Fig. 3 Individual patient 6-min walk test distances over time following treatment with elosulfase alfa. Note for patient 28, distance improved to $153 \mathrm{~m}$, but this was with a walker and has not been included on the figure. $1171 \mathrm{~A}>\mathrm{G}$ : founder pathogenic variant
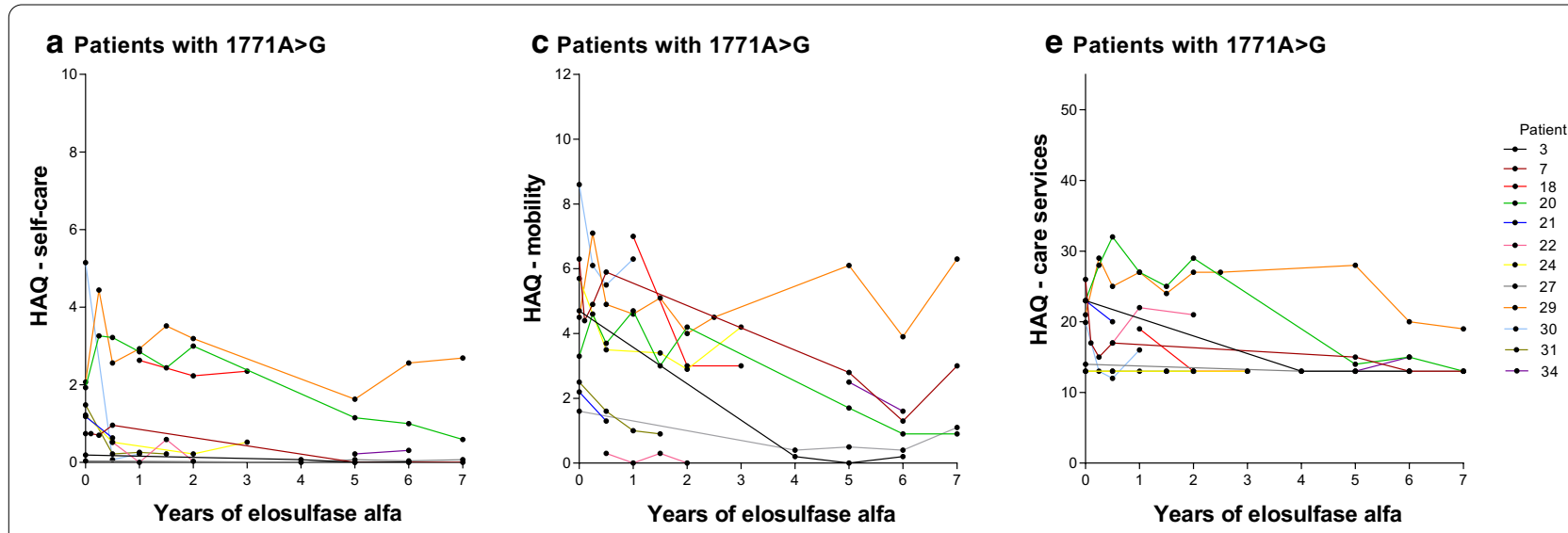

b Patients with non-1771A>G

d Patients with non-1771A>G

f Patients with non-1771A>G
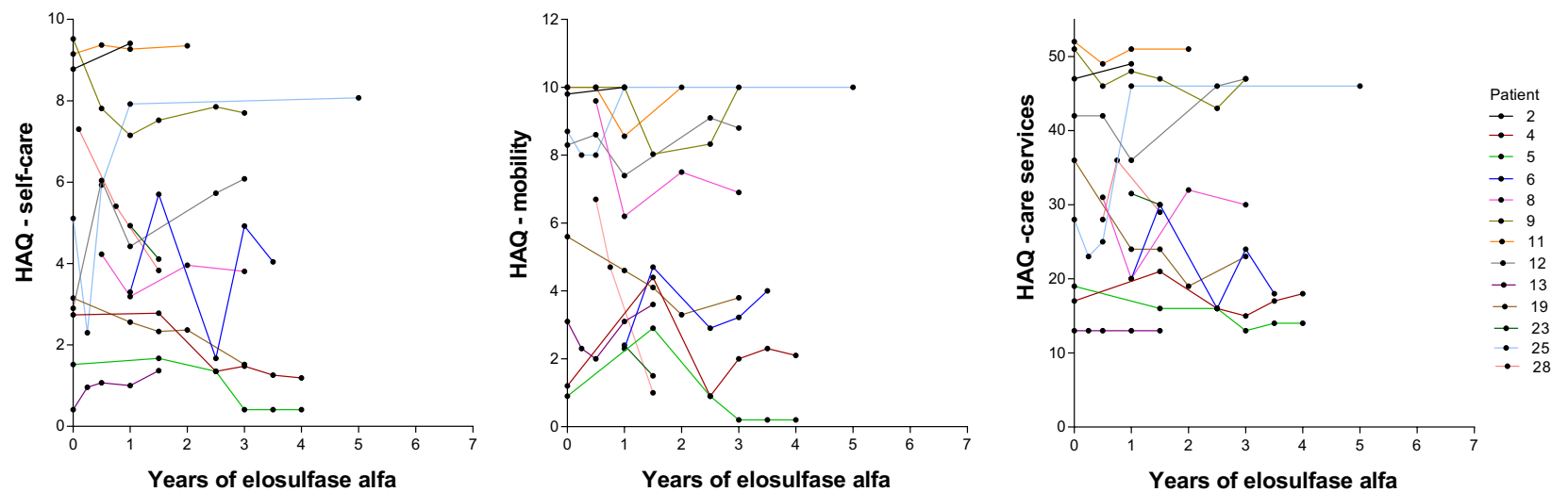

Fig. 4 Individual patient MPS-HAQ scores over time for the domains of self-care, mobility, and care services, following treatment with elosulfase alfa. Note that lower scores indicate a better outcome. 1171A>G: founder pathogenic variant; HAQ: Health Assessment Questionnaire 
which may also have introduced some variability in the results. There were limitations with the scoring systems used and the expectation of improvement with treatment. For patients who have normal or near-normal scores in a test at baseline, stability may be an important outcome. Finally, our data are incomplete for several reasons: not all patients in Quebec with Morquio A syndrome gave consent for participation; many patients needed to travel long distances which may have resulted in missed data points; the $6 \mathrm{MWT}$ and MPS-HAQ were not routinely performed in all patients; assessments were not always performed in the recommended time window due to e.g. surgeries; and some patients were too young to complete the respiratory function tests. However, despite missing data, the available data were sufficient to show significant differences in clinical characteristics between the founder pathogenic variant and the non-founder pathogenic variant groups.

\section{Conclusions}

Morquio A syndrome is a progressively debilitating lysosomal storage disorder that is heterogeneous in presentation and concentrated in the Quebecois population. We demonstrated a founder effect in French Canadians from Quebec with Morquio A, which manifests as a non-classical form of the disease related to the founder pathogenic variant in about half of the study population. Despite the observed founder effect, Quebecois patients did not appear to respond differently to therapy than patients in other Morquio A populations represented in clinical trials of elosulfase alfa. Improvements or stability in the 6MWT and/or MPS-HAQ in treated patients were seen regardless of GALNS pathogenic variant and were in line with those reported for patients in the clinical trials. Overall, the results of our study confirm published evidence for the beneficial effects of elosulfase alfa across multiple domains over both short and long time periods. In addition, they support the treatment plan proposed by the Canadian management guidelines, which involves initiation of treatment as early as possible, a cohesive follow-up approach, and establishment of individual treatment goals based on disease/functional stabilization and/or prevention of symptom onset [27]. Nevertheless, since enzyme replacement therapy with elosulfase alfa only partially improves the health and function of patients with Morquio A syndrome, continued research to develop additional disease-modifying treatments is needed.

\section{Abbreviations}

6MWT: 6-Min walk test; ADL: Activities of daily living; C6S: Chondroitin-6-sulfate; FEV : Forced expiratory volume in $1 \mathrm{~s}$; FVC: Forced vital capacity; GAGs: Glycosaminoglycans; GALNS: N-Acetylgalactosamine-6-sulfatase; ID: Patient identification number; KS: Keratan sulfate; MPS: Mucopolysaccharidosis; MPS-HAQ: Mucopolysaccharidosis Health Assessment Questionnaire; NA: Not available; NT: No elosulfase alfa treatment.

\section{Acknowledgements}

The authors would like to thank all study participants. Medical writing assistance was provided by Janelle Keys, PhD, CMPP, of ProScribe-Envision Pharma Group and by Ismar Healthcare, and was funded by BioMarin Pharmaceutical Inc. All medical writing services complied with international guidelines for Good Publication Practice (GPP3).

\section{Authors' contributions}

All authors participated in the collection of the data, interpretation of study results, and in the drafting and critical revision of the manuscript. All authors read and approved the final manuscript.

\section{Funding}

BioMarin Pharmaceutical Inc. provided financial support for the preparation of this manuscript, but was not involved in any aspects of manuscript preparation.

\section{Availability of data and materials}

The datasets used and/or analysed during the current study are available from the corresponding author on reasonable request.

\section{Ethics approval and consent to participate}

The study protocol was approved by the institutional review board at McGill University. All patients (or their guardians) provided written informed consent before study entry. The study was conducted in accordance with the Declaration of Helsinki and International Conference of Harmonization Good Clinical Practice guidelines.

\section{Consent for publication \\ Not applicable.}

\section{Competing interests}

JJM has been an investigator on clinical trials with BioMarin, Takeda, Ultragenyx, Enzyvant, and Sanofi-Genzyme, and has received consulting fees from BioMarin, Ultragenyx, Enzyvant and Sanofi-Genzyme; PMC is an investigator on the BioMarin MARS study and has received consulting fees from BioMarin; $\mathrm{BM}$ is an investigator on the BioMarin MARS study; all other authors have no conflicts of interest to declare.

\section{Author details \\ ${ }^{1}$ Division of Medical Genetics, Montreal Children's Hospital, McGill University Health Centre, Montreal, QC, Canada. ${ }^{2}$ Medical Genetics Division, Centre Hos- pitalier Universitaire Sherbrooke, Sherbrooke, QC, Canada. ${ }^{3}$ Medical Genetics Division, Department of Pediatrics, Centre Hospitalier Universitaire Sainte- Justine, Montreal, QC, Canada. ${ }^{4}$ Division of Pediatric Endocrinology, Montreal Children's Hospital, McGill University Health Centre, A04.6309, 1001 Decarie, Montreal, QC, Canada.}

Received: 23 April 2020 Accepted: 14 September 2020

Published online: 29 September 2020

\section{References}

1. Harmatz PR, Mengel KE, Giugliani R, Valayannopoulos V, Lin SP, Parini R, Guffon N, Burton BK, Hendriksz CJ, Mitchell JJ, Martins AM, Jones SA, Guelbert N, Vellodi A, Wijburg FA, Yang K, Slasor P, Decker C. Longitudinal analysis of endurance and respiratory function from a natural history study of Morquio A syndrome. Mol Genet Metab. 2015;114:186-94.

2. Tomatsu S, Yasuda E, Patel P, Ruhnke K, Shimada T, Mackenzie WG, Mason R, Thacker MM, Theroux M, Montaño AM, Alméciga-Diaz CJ, Barrera LA, Chinen Y, Sly WS, Rowan D, Suzuki Y, Orii T. Morquio A syndrome: diagnosis and current and future therapies. Pediatr Endocrinol Rev. 2014;12(Suppl 1):141-51.

3. Hendriksz CJ, Lavery C, Coker M, Ucar SK, Jain M, Bell L, Lampe C. Burden of disease in patients with Morquio A syndrome: results from an 
international patient-reported outcomes survey. Orphanet J Rare Dis. 2014;9:32.

4. Schrover R, Evans K, Giugliani R, Noble I, Bhattacharya K. Minimal clinically important difference for the 6-min walk test: literature review and application to Morquio A syndrome. Orphanet J Rare Dis. 2017;12:78.

5. Khan SA, Peracha H, Ballhausen D, Wiesbauer A, Rohrbach M, Gautschi M, Mason RW, Giugliani R, Suzuki Y, Orii KE, Orii T, Tomatsu S. Epidemiology of mucopolysaccharidoses. Mol Genet Metab. 2017;121:227-40.

6. Jezela-Stanek A, Rozdzynska-Swiatkowska A, Kulpanovich A, Ciara E, Marucha J, Tylki-Szymanska A. Novel data on growth phenotype and causative genotypes in 29 patients with Morquio (Morquio-Brailsford) syndrome from Central-Eastern Europe. J Appl Genet. 2019;60:163-74.

7. Hendriksz CJ, Berger Kl, Giugliani R, Harmatz P, Kampmann C, Mackenzie WG, Raiman J, Villarreal MS, Savarirayan R. International guidelines for the management and treatment of Morquio A syndrome. Am J Med Genet A. 2015;167A:11-25

8. Lavery C, Hendriksz C. Mortality in patients with Morquio syndrome A. JIMD Rep. 2015;15:59-66.

9. Leadley RM, Lang S, Misso K, Bekkering T, Ross J, Akiyama T, Fietz M, Giugliani R, Hendriksz CJ, Hock NL, McGill J, Olaye A, Jain M, Kleijnen J. A systematic review of the prevalence of morquio A syndrome: challenges for study reporting in rare diseases. Orphanet J Rare Dis. 2014;9:173.

10. Gadbois P, Moreau J, Laberge C. Morquio's disease in the province of Quebec. Union Med Can. 1973;102:602-7.

11. Casals F, Hodgkinson A, Hussin J, Idaghdour Y, Bruat $V$, de Maillard T, Grenier JC, Gbeha E, Hamdan FF, Girard S, Spinella JF, Lariviere M, Saillour V, Healy J, Fernandez I, Sinnett D, Michaud JL, Rouleau GA, Haddad E, Le Deist F, Awadalla P. Whole-exome sequencing reveals a rapid change in the frequency of rare functional variants in a founding population of humans. PLoS Genet. 2013;9:e1003815.

12. Health Canada. Summary basis of decision-Vimizim. https:// hpr-rps.hres.ca/reg-content/summary-basis-decision-detailTwo. php?lang=en\&linkID=SBD00199. Accessed July 2020.

13. Hendriksz CJ, Burton B, Fleming TR, Harmatz P, Hughes D, Jones SA, Lin SP, Mengel E, Scarpa M, Valayannopoulos V, Giugliani R, Slasor P, Lounsbury D, Dummer W, STRIVE Investigators. Efficacy and safety of enzyme replacement therapy with BMN 110 (elosulfase alfa) for Morquio A syndrome (mucopolysaccharidosis IVA): a phase 3 randomised placebocontrolled study. J Inherit Metab Dis. 2014;37:979-90.

14. Hendriksz CJ, Parini R, AISayed MD, Raiman J, Giugliani R, Solano Villarreal ML, Mitchell JJ, Burton BK, Guelbert N, Stewart F, Hughes DA, Berger Kl, Slasor P, Matousek R, Jurecki E, Shaywitz AJ, Harmatz PR. Long-term endurance and safety of elosulfase alfa enzyme replacement therapy in patients with Morquio A syndrome. Mol Genet Metab. 2016;1 19:131-43.

15. Hendriksz C, Santra S, Jones SA, Geberhiwot T, Jesaitis L, Long B, Qi Y, Hawley SM, Decker C. Safety, immunogenicity, and clinical outcomes in patients with Morquio A syndrome participating in 2 sequential open-label studies of elosulfase alfa enzyme replacement therapy (MOR002/MOR-100), representing 5 years of treatment. Mol Genet Metab. 2018;123:479-87.

16. McMillan HJ, Campbell C. We need a "made in Canada" orphan drug framework. CMAJ. 2017;189:E1274-5.

17. von Elm E, Altman DG, Egger M, Pocock SJ, Gotzsche PC, Vandenbroucke JP. The strengthening the reporting of observational studies in epidemiology (STROBE) statement: guidelines for reporting observational studies. Bull World Health Organ. 2007;85:867-72.

18. Tomatsu S, Montaño AM, Nishioka T, Gutierrez MA, Peña OM, Trandafirescu GG, Lopez P, Yamaguchi S, Noguchi A, Orii T. Mutation and polymorphism spectrum of the GALNS gene in mucopolysaccharidosis IVA (Morquio A). Hum Mutat. 2005;26:500-12.

19. https://apps.cpeg-gcep.net/quickZ_WHO. Accessed July 2020.

20. Hendriksz CJ, Parini R, AlSayed M, Raiman J, Giugliani R, Mitchell J, Burton BK, Guelbert N, Stewart FJ, Hughes DA, Matousek R, Hawley SM, Decker C, Harmatz PR. Impact of long-term elosulfase alfa on activities of daily living in patients with morquio a syndrome in an open-label, multi-center, phase 3 extension study. Mol Genet Metab. 2018;123:127-34.

21. Harmatz $P$, Mengel KE, Giugliani R, Valayannopoulos V, Lin SP, Parini R, Guffon N, Burton BK, Hendriksz CJ, Mitchell J, Martins A, Jones S, Guelbert N, Vellodi A, Hollak C, Slasor P, Decker C. The Morquio A Clinical Assessment Program: baseline results illustrating progressive, multisystemic clinical impairments in Morquio A subjects. Mol Genet Metab. 2013;109:54-61.

22. Burton BK, Berger KI, Lewis GD, Tarnopolsky M, Treadwell M, Mitchell JJ, Muschol N, Jones SA, Sutton VR, Pastores GM, Lau H, Sparkes R, Genter F, Shaywitz AJ, Harmatz P. Safety and physiological effects of two different doses of elosulfase alfa in patients with Morquio A syndrome: a randomized, double-blind, pilot study. Am J Med Genet A. 2015;167A:2272-81.

23. Montaño AM, Tomatsu S, Brusius A, Smith M, Orii T. Growth charts for patients affected with Morquio A disease. Am J Med Genet A. 2008;146A:1286-95.

24. Hughes D, Giugliani R, Guffon N, Jones SA, Mengel KE, Parini R, Matousek R, Hawley SM, Quartel A. Clinical outcomes in a subpopulation of adults with Morquio A syndrome: results from a long-term extension study of elosulfase alfa. Orphanet J Rare Dis. 2017;12:98.

25. Lammers AE, Hislop AA, Flynn Y, Haworth SG. The 6-minute walk test: normal values for children of 4-11 years of age. Arch Dis Child. 2008;93:464-8

26. Li AM, Yin J, Au JT, So HK, Tsang T, Wong E, Fok TF, Ng PC. Standard reference for the six-minute-walk test in healthy children aged 7 to 16 years. Am J Respir Crit Care Med. 2007;176:174-80.

27. Clark LA, Campeau P, Danielson D, et al. Canadian expert opinion: recommendations for the use of elosulfase alfa in the management of Morquio A syndrome (MPS IVA) 2016. https://www.researchgate.net/publicatio n/273058862_Canadian_expert_opinion_Recommendations_for_the_ use_of_Elosulfase_alfa_in_the_management_of_Morquio_A_syndr ome_MPS_IVA. Accessed July 2020.

28. Akyol MU, Alden TD, Amartino H, Ashworth J, Belani K, Berger Kl, Borgo A, Braunlin E, Eto Y, Gold JI, Jester A, Jones SA, Karsli C, Mackenzie W, Marinho DR, McFadyen A, McGill J, Mitchell JJ, Muenzer J, Okuyama T, Orchard PJ, Stevens B, Thomas S, Walker R, Wynn R, Giugliani R, Harmatz P, Hendriksz C, Scarpa M, Committee MPSCPS, Co-Chairs MPSCP. Recommendations for the management of MPS IVA: systematic evidence- and consensus-based guidance. Orphanet J Rare Dis. 2019;14:137.

29. Casanova C, Celli BR, Barria P, Casas A, Cote C, de Torres JP, Jardim J, Lopez MV, Marin JM, Montes de Oca M, Pinto-Plata V, Aguirre-Jaime A, Six Minute Walk Distance Project (ALAT). The 6-min walk distance in healthy subjects: reference standards from seven countries. Eur Respir J. 2011;37:150-6.

\section{Publisher's Note}

Springer Nature remains neutral with regard to jurisdictional claims in published maps and institutional affiliations. 